\title{
On the interpolation of isoelectronic data
}

\author{
A. Burgess ${ }^{1}$, M.C. Chidichimo ${ }^{2}$, and J.A. Tully ${ }^{3}$ \\ 1 Department of Applied Mathematics and Theoretical Physics, Silver Street, Cambridge CB3 9EW, UK \\ 2 Department of Applied Mathematics, University of Waterloo, Waterloo, Ontario, Canada N2L 3G1 \\ 3 Département G.D. Cassini, Observatoire de la Côte d'Azur, BP. 4229, 06304 Nice Cedex 4, France
}

Received February 23; accepted May 20, 1996

\begin{abstract}
The program developed by Burgess for spline fitting and interpolating collision strengths can also be used to do isoelectronic fits. Instead of treating $\Omega(E)$ or $\Upsilon(T)$ one inputs an arbitrary quantity $A(Z)$ that is a function of nuclear charge number $Z$. In this way isoelectronic atomic data can be visualised and compacted in an easy manner which allows for accurate interpolation along a sequence. Four illustrative applications are provided.
\end{abstract}

Key words: isoelectronic sequence - atomic data spline interpolation

\section{Introduction}

Atomic quantities such as oscillator strengths, spectral line wavelengths, energy levels and ionization potentials depend on the nuclear charge number $Z$. Methods of plotting such atomic data along isoelectronic sequences have been in use for a long time. For example, this was how Edlén (1942) showed that the mysterious green coronal line originates from a forbidden transition within the ground configuration of Fe XIV. He had the simple but astute idea of plotting essentially the fourth root of the ground term splitting $\Delta \sigma$ as a function of $Z$. The resulting reduced splittings deduced from laboratory spectra of neutral aluminium and the first eight ions of the sequence lie on a smooth curve. When extended to higher values of $Z$ the curve is seen to coincide with the coronal lines $\lambda 5303$ and $\lambda 3601$, assuming they come from Fe XIV and Ni XVI respectively.

Here we show how the program OMEUPS developed by Burgess (see Burgess \& Tully 1992) can be used for exhibiting and spline fitting atomic data along an isoelectronic sequence. Instead of inputting the collision strength $\Omega(E)$ as a function of the final collision energy $E$, we input $A(Z)$ where $A$ is the quantity under study and $Z$ is the atomic, or nuclear charge, number. An attractive

Send offprint requests to: A. Burgess feature of OMEUPS is that it makes use of interactive graphics. The program transforms $A(Z)$ to a reduced form $A_{\mathrm{r}}\left(Z_{\mathrm{r}}\right)$ where the reduced charge number $Z_{\mathrm{r}}$ varies from zero when $Z=Z_{0}$ to unity when $Z=\infty$. The value assigned to $Z_{0}$ determines the range of elements we wish to include. In general we assume $Z_{0}=N$, where $N$ is the number of bound electrons, so that the range includes the neutral atom and all positive ions. A parameter $C$ occurs in the definition of $Z_{\mathrm{r}}$ to provide a useful degree of flexibility for modifying the plot. By varying the value of $C$ one alters the way in which the data points are distributed across the figure. In many cases $A_{\mathrm{r}}\left(Z_{\mathrm{r}}\right)$ tends to a finite limit at $Z_{\mathrm{r}}=1$ which can be determined. This is often helpful when approximating the data points by a least squares 5 point cubic spline. The program carries out the spline fitting procedure efficiently and rapidly.

We compare our method with Edlén's for a fine structure transition in the aluminium sequence (see Fig. 3) and give other examples to show the usefulness and versatility of the present approach.

Preliminary versions of the examples given here were presented at the 5th International Colloquium on Atomic Spectra and Oscillator Strengths for Astrophysical and Laboratory Plasmas which was held at the Observatoire de Paris (Meudon) from 28 to 31 August 1995.

\section{Fitting isoelectronic data}

The reduced charge number $Z_{\mathrm{r}}$ is defined by

$Z_{\mathrm{r}}=\frac{Z-Z_{0}}{Z-Z_{0}+C}$

where $Z$ is the atomic number (i.e. nuclear charge in atomic units) for which the range is $Z_{0} \leq Z<\infty$. $Z_{0}$ is usually equal to the number of bound electrons $N$ although on occasions it is more convenient if $Z_{0}>N$ as in the second example (Fig. 2) where $Z_{0}=N+1$. Here we omit the neutral atom case and consequently obtain a much better fit to the positive ion data points. The parameter $C$ is adjusted in order to optimise the spline fit. The plots we use are either of type $2(A \sim$ constant for 


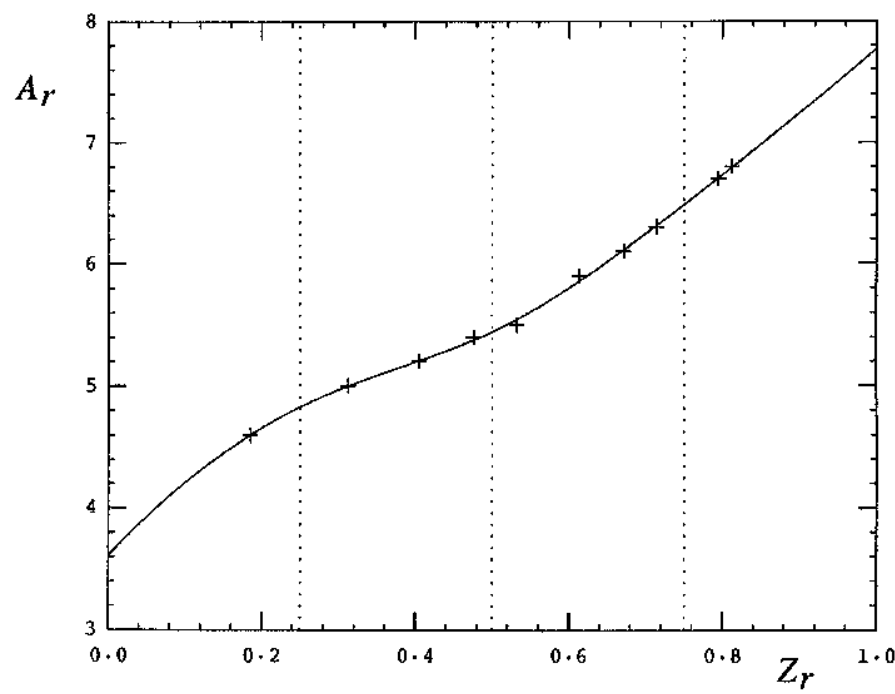

Fig. 1. Fluorine sequence: $A_{\mathrm{r}} \equiv \log \left(T_{\max }\right), Z_{\mathrm{o}}=N=9$, $C=4.4$

large $Z)$ or type $3\left(A \sim Z^{-2}\right.$ for large $\left.Z\right)$. The different types of plot are defined and discussed by Burgess \& Tully (1992).

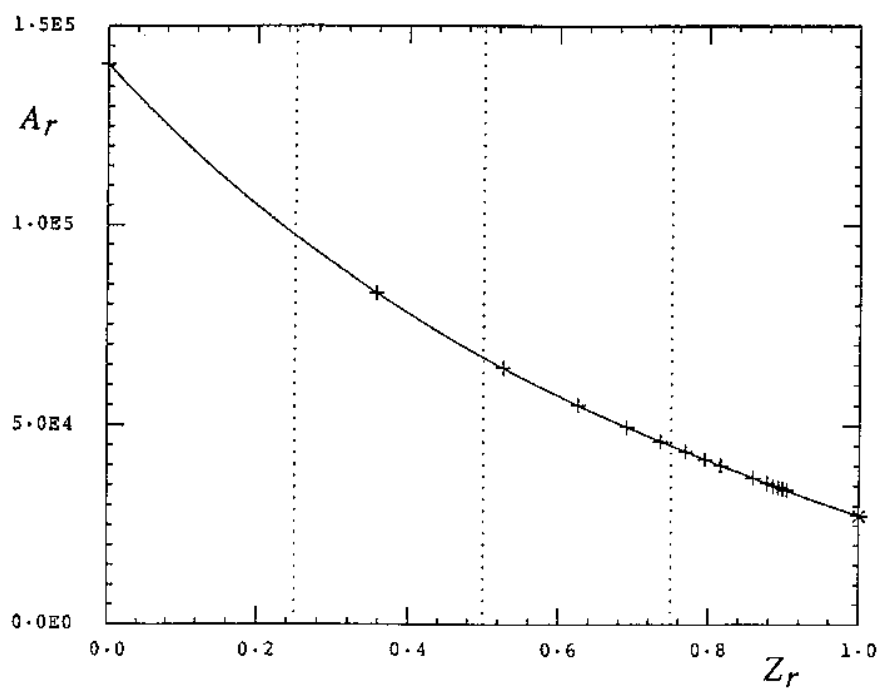

Fig. 2. Fluorine sequence: $A_{\mathrm{r}} \equiv I /\left(Z-Z_{0}+1\right)^{2}, Z_{0}=N=9$, $C=1.8$

\subsection{Type 2 plots}

Figure 1 concerns temperatures of maximum abundance $T_{\max }$ for fluorine-like ions in conditions of coronal ionization equilibrium. From Arnaud \& Rothenflug's (1985) tabulation we obtain estimates of $\log \left(T_{\max }\right)$ for 10 ions in the sequence. Our spline fit can be used to complete their tabulation for the intermediate ions which they did not consider. Here we input $A \equiv \log \left(T_{\max }\right)$ and treat it as a type 2 case. The optimised fit has $C=4.4$ and rms error $0.38 \%$. Since we only wish to interpolate the data but not extrapolate them, we are not concerned with the high $Z$ limit point. In fact it does not exist since there is a weak (logarithmic) divergence in this case.

Figure 2 deals with the ionization energy $I$ of fluorinelike ions. Since $I$ increases like $Z^{2}$ as $Z$ tends to $\infty$, we treat this as type 2 by inputting $A \equiv I /(Z-N+1)^{2}$, with $I$ in $\mathrm{cm}^{-1}$. The limit point at $Z_{\mathrm{r}}=1$ corresponding to $Z \rightarrow \infty$ is the hydrogenic value $R_{\infty} / 4=27434$, while the optimised fit (rms error $0.16 \%$ ) is obtained with $C=1.8$.

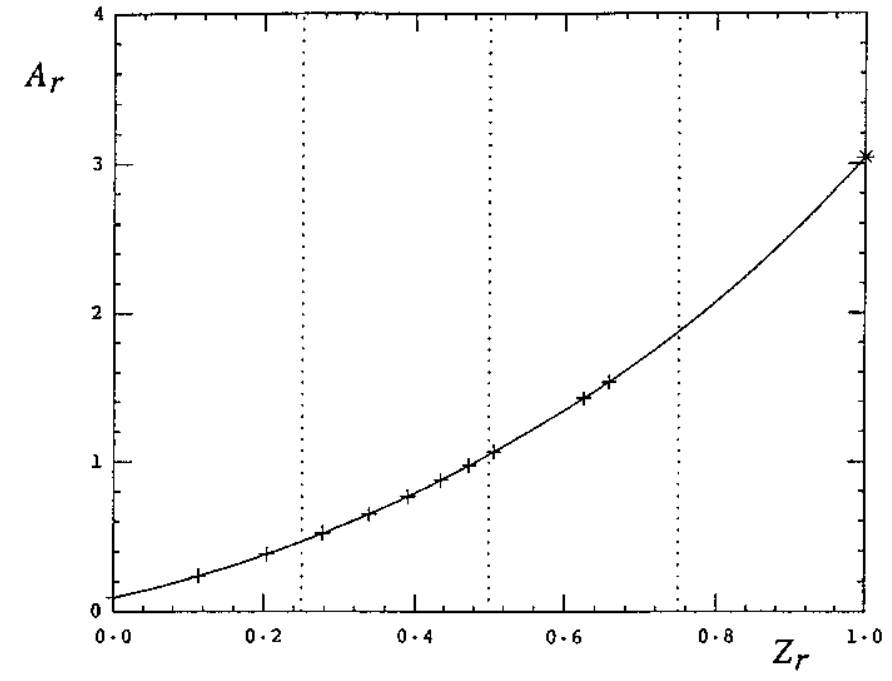

Fig. 3. Aluminium sequence: $A_{\mathrm{r}} \equiv\left(Z-Z_{0}+1\right)^{2} /(\Delta \sigma)^{1 / 2}$, $Z_{0}=N=13, C=7.8$

\subsection{Type 3 plots}

Figure 3 shows our way of interpolating the ground term magnetic dipole transition energies for the aluminium sequence. It is instructive to compare this way of plotting the data with that used by Edlén (1942) in his Fig. 1. We invert the observed spin-orbit splitting $\Delta \sigma$ of the $3 \mathrm{~s}^{2} 3 \mathrm{p}^{2} \mathrm{P}^{\circ}$ term, which Edlén (1942) gives in $\mathrm{cm}^{-1}$ in Table 2 , and take the square root. This yields a quantity $A \equiv(\Delta \sigma)^{-1 / 2} \sim Z^{-2}$ at high $Z$. The value of the limit point for this type 3 plot is

$\operatorname{Lim}_{Z \rightarrow \infty}\left[A(Z) Z^{2}\right]=\left(54 / R_{\infty} \alpha^{2}\right)^{1 / 2}=3.040 \mathrm{~cm}^{1 / 2}$,

and is deduced from the well-known expression for the spin-orbit splitting given by Edlén (1964, p. 167), viz.

$\Delta \sigma=R_{\infty} \alpha^{2}(54)^{-1}\left(Z-s^{\prime}\right)^{4}$,

where the screening parameter $s^{\prime}>0$ is a finite quantity which varies slowly with $Z$. The optimised spline fit (rms 
Table 1. Spline fitting parameters for the curves shown in the figures

$\begin{array}{lllllll}\text { Figure } & 1 & 2 & 3 & 4(0-1) & 4(0-2) & 4(1-2) \\ \text { Type } & 2 & 2 & 3 & 3 & 3 & 3 \\ C & 4.4 & 1.8 & 7.8 & 4.1 & 4.4 & 4.2 \\ P_{1} & 3.609 \mathrm{E}+0 & 1.406 \mathrm{E}+5 & 9.447 \mathrm{E}-2 & 3.560 \mathrm{E}-1 & 2.440 \mathrm{E}-1 & 9.950 \mathrm{E}-1 \\ P_{2} & 4.830 \mathrm{E}+0 & 9.742 \mathrm{E}+4 & 4.643 \mathrm{E}-1 & 2.053 \mathrm{E}+0 & 1.240 \mathrm{E}+0 & 5.317 \mathrm{E}+0 \\ P_{3} & 5.442 \mathrm{E}+0 & 6.674 \mathrm{E}+4 & 1.049 \mathrm{E}+0 & 4.975 \mathrm{E}+0 & 2.673 \mathrm{E}+0 & 1.217 \mathrm{E}+1 \\ P_{4} & 6.485 \mathrm{E}+0 & 4.491 \mathrm{E}+4 & 1.877 \mathrm{E}+0 & 7.451 \mathrm{E}+0 & 4.156 \mathrm{E}+0 & 1.859 \mathrm{E}+1 \\ P_{5} & 7.770 \mathrm{E}+0 & 2.746 \mathrm{E}+4 & 3.040 \mathrm{E}+0 & 7.520 \mathrm{E}+0 & 5.910 \mathrm{E}+0 & 2.270 \mathrm{E}+1 \\ \text { error } & 0.38 \% & 0.16 \% & 0.05 \% & 0.10 \% & 0.13 \% & 0.05 \%\end{array}$

Table 2. (a) $\log \left(T_{\max }\right)$ from the spline fit shown in Fig. 1. $T_{\max }$ is the temperature of maximum coronal abundance for F-like ions. (b) Ionization energy in $\mathrm{cm}^{-1}$ for F-like ions deduced from the spline fit shown in Fig. 2. The results given here are calculated using data from Table 1

$\begin{array}{llllll}\text { Ion } & \mathrm{F} & \mathrm{Ne}^{+} & \mathrm{Na}^{+2} & \mathrm{Mg}^{+3} & \mathrm{Al}^{+4} \\ \text { (a) } & 3.609 & 4.600 & 4.999 & 5.205 & 5.375 \\ \text { (b) } & 1.406 \mathrm{E}+5 & 3.316 \mathrm{E}+5 & 5.770 \mathrm{E}+5 & 8.806 \mathrm{E}+5 & 1.241 \mathrm{E}+6 \\ & & & & & \\ \text { Ion } & \mathrm{Si}^{+5} & \mathrm{P}^{+6} & \mathrm{~S}^{+7} & \mathrm{Cl}^{+8} & \mathrm{Ar}^{+9} \\ \text { (a) } & 5.543 & 5.706 & 5.857 & 5.991 & 6.111 \\ \text { (b) } & 1.658 \mathrm{E}+6 & 2.129 \mathrm{E}+6 & 2.655 \mathrm{E}+6 & 3.236 \mathrm{E}+6 & 3.871 \mathrm{E}+6 \\ & & & & & \\ \text { Ion } & \mathrm{K}^{+10} & \mathrm{Ca}^{+11} & \mathrm{Sc}^{+12} & \mathrm{Ti}^{+13} & \mathrm{~V}^{+14} \\ \text { (a) } & 6.217 & 6.312 & 6.396 & 6.471 & 6.538 \\ \text { (b) } & 4.562 \mathrm{E}+6 & 5.307 \mathrm{E}+6 & 6.107 \mathrm{E}+6 & 6.962 \mathrm{E}+6 & 7.872 \mathrm{E}+6 \\ & & & & & \\ \text { Ion } & \mathrm{Cr}^{+15} & \mathrm{Mn}^{+16} & \mathrm{Fe}+17 & \mathrm{Co}^{+18} & \mathrm{Ni} \\ \text { (a) } & 6.599 & 6.654 & 6.704 & 6.750 & 6.792 \\ \text { (b) } & 8.837 \mathrm{E}+6 & 9.856 \mathrm{E}+6 & 1.093 \mathrm{E}+7 & 1.206 \mathrm{E}+7 & 1.324 \mathrm{E}+7 \\ & & & & & \end{array}$

Table 3. Transition energy in $\mathrm{cm}^{-1}$ for the fine structure splitting in the ground configuration of aluminium and Al-like ions. (a) Using the spline interpolation data given in Table 1. (b) Using Edlén's (1964) extrapolation formula

$\begin{array}{llllll}\text { Ion } & \mathrm{Al} & \mathrm{Si}^{+} & \mathrm{P}^{+2} & \mathrm{~S}^{+3} & \mathrm{Cl}^{+4} \\ \text { (a) } & 1.121 \mathrm{E}+2 & 2.870 \mathrm{E}+2 & 5.599 \mathrm{E}+2 & 9.520 \mathrm{E}+2 & 1.491 \mathrm{E}+3 \\ \text { (b) } & 1.144 \mathrm{E}+2 & 2.873 \mathrm{E}+2 & 5.587 \mathrm{E}+2 & 9.512 \mathrm{E}+2 & 1.491 \mathrm{E}+3 \\ & & & & & \\ \text { Ion } & \mathrm{Ar}^{+5} & \mathrm{~K}^{+6} & \mathrm{Ca}^{+7} & \mathrm{Sc}^{+8} & \mathrm{Ti}^{+9} \\ \text { (a) } & 2.207 \mathrm{E}+3 & 3.133 \mathrm{E}+3 & 4.307 \mathrm{E}+3 & 5.767 \mathrm{E}+3 & 7.555 \mathrm{E}+3 \\ \text { (b) } & 2.208 \mathrm{E}+3 & 3.134 \mathrm{E}+3 & 4.306 \mathrm{E}+3 & 5.761 \mathrm{E}+3 & 7.542 \mathrm{E}+3 \\ & & & & & \\ \text { Ion } & \mathrm{V}^{+10} & \mathrm{Cr}^{+11} & \mathrm{Mn}^{+12} & \mathrm{Fe}^{+13} & \mathrm{Co}^{+14} \\ \text { (a) } & 9.714 \mathrm{E}+3 & 1.229 \mathrm{E}+4 & 1.532 \mathrm{E}+4 & 1.887 \mathrm{E}+4 & 2.299 \mathrm{E}+4 \\ \text { (b) } & 9.692 \mathrm{E}+3 & 1.226 \mathrm{E}+4 & 1.530 \mathrm{E}+4 & 1.885 \mathrm{E}+4 & 2.299 \mathrm{E}+4\end{array}$

error of $0.05 \%$ ) is obtained when $C=7.8$. Edlén's (1964) extrapolation formula for $Z-s^{\prime}$ as a function of $Z$ is given by the pair of equations

$$
\begin{gathered}
s^{\prime}=s-31 \alpha^{2}\left(Z-s^{\prime}\right)^{3} / 192 \\
s=5.3124+6.689(Z-9.7)^{-1}-0.00306 Z
\end{gathered}
$$

which reduces to finding the roots of the cubic equation (Maple 1995)

$a\left(Z-s^{\prime}\right)^{3}-\left(Z-s^{\prime}\right)+b=0$,
Table 4. Fine structure collision strengths $\Omega\left(J, J^{\prime}\right)$ at zero energy for the ground ${ }^{3} \mathrm{P}$ term in C-like ions. (a) $\Omega(0,1)$; (b) $\Omega(0,2)$; (c) $\Omega(1,2)$. Results obtained using the interpolating spline fit given in Table 1

$\begin{array}{llllll}\text { Ion } & \mathrm{N}^{+} & \mathrm{O}^{+2} & \mathrm{~F}^{+3} & \mathrm{Ne}^{+4} & \mathrm{Na}^{+5} \\ \text { (a) } & 3.56 \mathrm{E}-1 & 3.89 \mathrm{E}-1 & 3.31 \mathrm{E}-1 & 2.51 \mathrm{E}-1 & 1.96 \mathrm{E}-1 \\ \text { (b) } & 2.44 \mathrm{E}-1 & 2.32 \mathrm{E}-1 & 1.75 \mathrm{E}-1 & 1.32 \mathrm{E}-1 & 1.01 \mathrm{E}-1 \\ \text { (c) } & 9.95 \mathrm{E}-1 & 1.01 \mathrm{E}+0 & 7.95 \mathrm{E}-1 & 6.11 \mathrm{E}-1 & 4.73 \mathrm{E}-1 \\ & & & & & \\ \text { Ion } & \mathrm{Mg}^{+6} & \mathrm{Al}^{+7} & \mathrm{Si}^{+8} & \mathrm{P}^{+9} & \mathrm{~S}^{+10} \\ \text { (a) } & 1.55 \mathrm{E}-1 & 1.24 \mathrm{E}-1 & 1.01 \mathrm{E}-1 & 8.35 \mathrm{E}-2 & 7.00 \mathrm{E}-2 \\ \text { (b) } & 7.94 \mathrm{E}-2 & 6.37 \mathrm{E}-2 & 5.22 \mathrm{E}-2 & 4.35 \mathrm{E}-2 & 3.68 \mathrm{E}-2 \\ \text { (c) } & 3.72 \mathrm{E}-1 & 2.98 \mathrm{E}-1 & 2.44 \mathrm{E}-1 & 2.02 \mathrm{E}-1 & 1.70 \mathrm{E}-1 \\ & & & & & \\ \text { Ion } & \mathrm{Cl}^{+11} & \mathrm{Ar}^{+12} & \mathrm{~K}^{+13} & \mathrm{Ca}^{+14} & \mathrm{Sc}+15 \\ \text { (a) } & 5.93 \mathrm{E}-2 & 5.08 \mathrm{E}-2 & 4.39 \mathrm{E}-2 & 3.83 \mathrm{E}-2 & 3.37 \mathrm{E}-2 \\ \text { (b) } & 3.15 \mathrm{E}-2 & 2.73 \mathrm{E}-2 & 2.39 \mathrm{E}-2 & 2.11 \mathrm{E}-2 & 1.88 \mathrm{E}-2 \\ \text { (c) } & 1.45 \mathrm{E}-1 & 1.25 \mathrm{E}-1 & 1.09 \mathrm{E}-1 & 9.55 \mathrm{E}-2 & 8.44 \mathrm{E}-2 \\ & & & & & \\ \text { Ion } & \mathrm{Ti} & & & & \\ \text { (a) } & 2.98 \mathrm{E}-2 & 2.66 \mathrm{E}-2 & 2.38 \mathrm{E}-2 & 2.14 \mathrm{E}-2 & 1.94 \mathrm{E}-2 \\ \text { (b) } & 1.68 \mathrm{E}-2 & 1.51 \mathrm{E}-2 & 1.37 \mathrm{E}-2 & 1.25 \mathrm{E}-2 & 1.14 \mathrm{E}-2 \\ \text { (c) } & 7.52 \mathrm{E}-2 & 6.74 \mathrm{E}-2 & 6.07 \mathrm{E}-2 & 5.49 \mathrm{E}-2 & 5.00 \mathrm{E}-2\end{array}$

where

$a=31 \alpha^{2} / 192$

and

$b=1.00306 Z-6.689(Z-9.7)^{-1}-5.3124$.

Only one of the roots of (5) is a physical solution, and its range of validity as a function of $Z$ is limited, since for $Z \geq 85$ the screening parameter $s^{\prime}$ becomes negative.

Figure 4 shows the compacting and interpolation of Blaha's (1969) distorted wave results for three fine structure collision strengths at threshold energy in the carbon sequence. The transitions are between the lowest three levels. Blaha gives results for neutral carbon and 7 ions in the sequence. Here we take $Z_{0}=N+1=7$ and input $A \equiv \Omega$ which decreases like $Z^{-2}$ as $Z \rightarrow \infty$. The high $Z$ limits for $Z^{2} \Omega$ are from Saraph et al. (1969).

\subsection{Spline fitting parameters}

The five knot values $P_{1}, P_{2}, P_{3}, P_{4}, P_{5}$ and $C$ parameter for each of the spline curves shown in Figs. 1 to 4 are given in 
Table 1. By means of the program FUNCTION SPLINE $\left(P_{1}, P_{2}, P_{3}, P_{4}, P_{5}, X\right), \quad$ (see Burgess \& Tully's 1992 Appendix), it is possible to interpolate the reduced data points shown in the figures. Notice that $X \equiv Z_{\mathrm{r}}$ and by using the definition of $Z_{\mathrm{r}}$ in terms of $Z, Z_{0}$ and $C$, and knowing the type of plot one can obtain $A(Z)$.

The interpolated results given in Tables 2,3 and 4 are calculated using data in Table 1 and the spline program from Burgess \& Tully (1992).

\section{References}

Arnaud M., Rothenflug R., 1985, A\&AS 60, 425

Blaha M., 1969, A\&A 1, 42

Burgess A., Tully J.A., 1992, A\&A 254, 436

Edlén B., 1942, Zeit. f. Astrophys. 22, 30

Edlén B., 1964, Atomic Spectra. In Handbuch der Physik, Vol. XXVII, Flügge S. (ed.). Berlin: Springer Verlag Maple V., 1995, Release 4, Waterloo Maple Inc.

Saraph H.E., Seaton M.J., Shemming J., 1969, Phil. Trans. Roy. Soc. A 264, 77

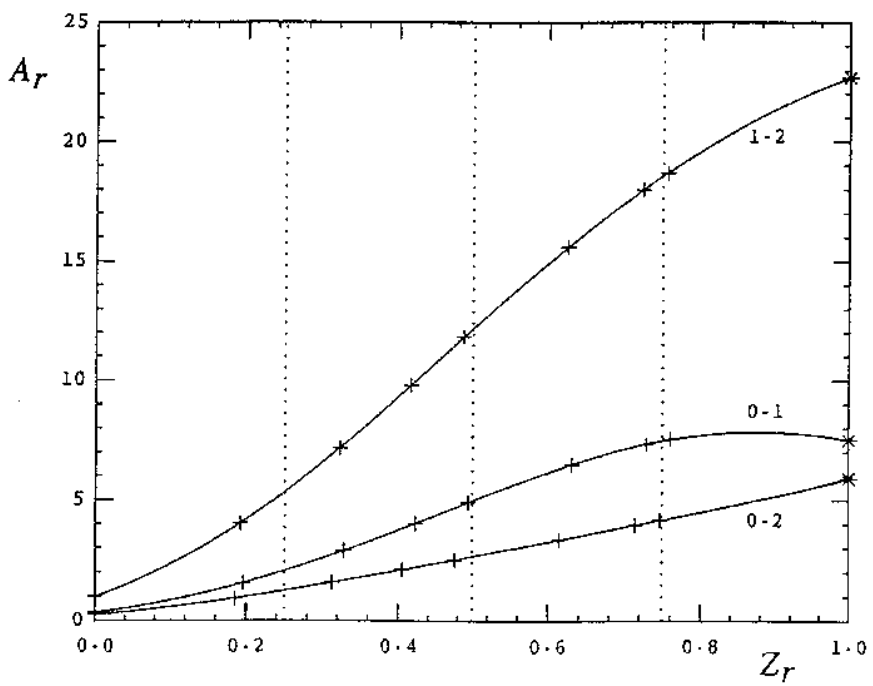

Fig. 4. Carbon sequence: $A_{\mathrm{r}} \equiv\left(Z-Z_{0}+1\right)^{2} \Omega\left(J, J^{\prime}\right)$, $Z_{0}=N+1=7, C_{0-1}=4.1, C_{0-2}=4.4, C_{1-2}=4.2$ 